\title{
Industriestrategie 2030 - Alter Wein in neuen Schläuchen?
}

\author{
Die industriepolitischen Pläne namens "Nationale Industriestrategie 2030" von \\ Bundeswirtschaftsminister Peter Altmaier werden derzeit kontrovers diskutiert. \\ Stark vereinfacht ausgedrückt sollen nationale Champions entstehen, einzelne \\ Branchen strategisch gefördert und unerwünschte Investoren abgewehrt \\ werden - etwa durch den Aufbau staatlicher Beteiligungsfonds.
}

\section{Pro von Jan Schnellenbach \\ Prof. Dr. Jan Schnellenbach ist seit Oktober 2014 Professor für Volks- wirtschaftslehre, insbesondere Mikroökono- mik an der BTU Cottbus-Senftenberg. Von 2012 bis 2014 war Schnellenbach geschäfts- führender Forschungsreferent des Walter- Eucken-Instituts in Freiburg sowie Privat- dozent an der Universität Heidelberg, an der er auch 2009 habilitierte und kurz darauf eine Vertretungsprofessur erhielt.}

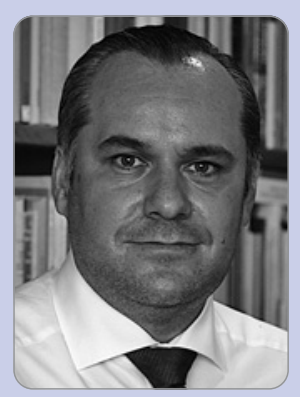

\section{Problem}

Deutschland steht ein möglicherweise schwerwiegender Strukturwandel bevor. Nicht nur die Automobilwirtschaft wird sich absehbar stark wandeln. Was kann die Politik tun?

\section{Vorstoß}

Altmaier setzt auf eine Industriepolitik, wie man sie am ehesten aus Frankreich kennt. Sie beinhaltet staatliche Investitionslenkung, das 0pfern von Wettbewerbsintensität, um "nationale Champions“ zu schaffen, sowie die Vorstellung, der Staat wisse am besten, wo sich Chancen für Innovationen bieten. Die Strategie fußt auf einer politischen Anmaßung von Wissen in großem Stil. Empirisch gibt es aber keine Anhaltspunkte dafür, dass diese Art von planerischer Industriepolitik dauerhaft erfolgreich ist.

\section{Folgen}

Die Strategie Altmaiers birgt die Gefahr, das dynamische, durch viele innovative Mittelständler geprägte deutsche Erfolgsmodell in eine sklerotische Rent-Seeking-Ökonomie zu transformieren. Staatliche Investitionslenkung verbrennt Geld in politisch interessanten, aber ökonomisch sinnlosen Projekten. "Champions" mit staatlicher Bestandsgarantie verlassen sich darauf, vor Wettbewerb geschützt zu werden, der eigentlich Antrieb jeder nachhaltigen Wachstumsdynamik ist. Die Industriestrategie hat das Potential, Deutschland bis zum Jahr 2030 zum „kranken Mann Europas” zu machen.

\section{Lösung}

Deutschland benötigt dringend eine Welle angebotspolitischer Reformen. Dazu gehören sinkende Steuern auf Einkommen und Gewinne, aber auch ein Abbau von Regulierungen, die gerade den Mittelständlern oft sehr hohe Bürokratiekosten aufbürden und ihr unternehmerisches Handeln erschweren. 


\section{Industriepolitik ist natürlich kein neues Phänomen. Es gab sie auch schon in den 1960er und 1970er Jahren. Doch die Welt hat sich zuletzt aufgrund der Digitalisierung und Globalisierung gleichermaßen stark gewandelt. Der Ökonom Jan Schnellenbach und der Politiker Oliver Wittke sind unterschied- licher Meinung, ob Altmaiers Vorstoß als alter Wein in neuen Schläuchen zu betrachten ist oder ob er tatsächlich ein großer Wurf werden kann.}

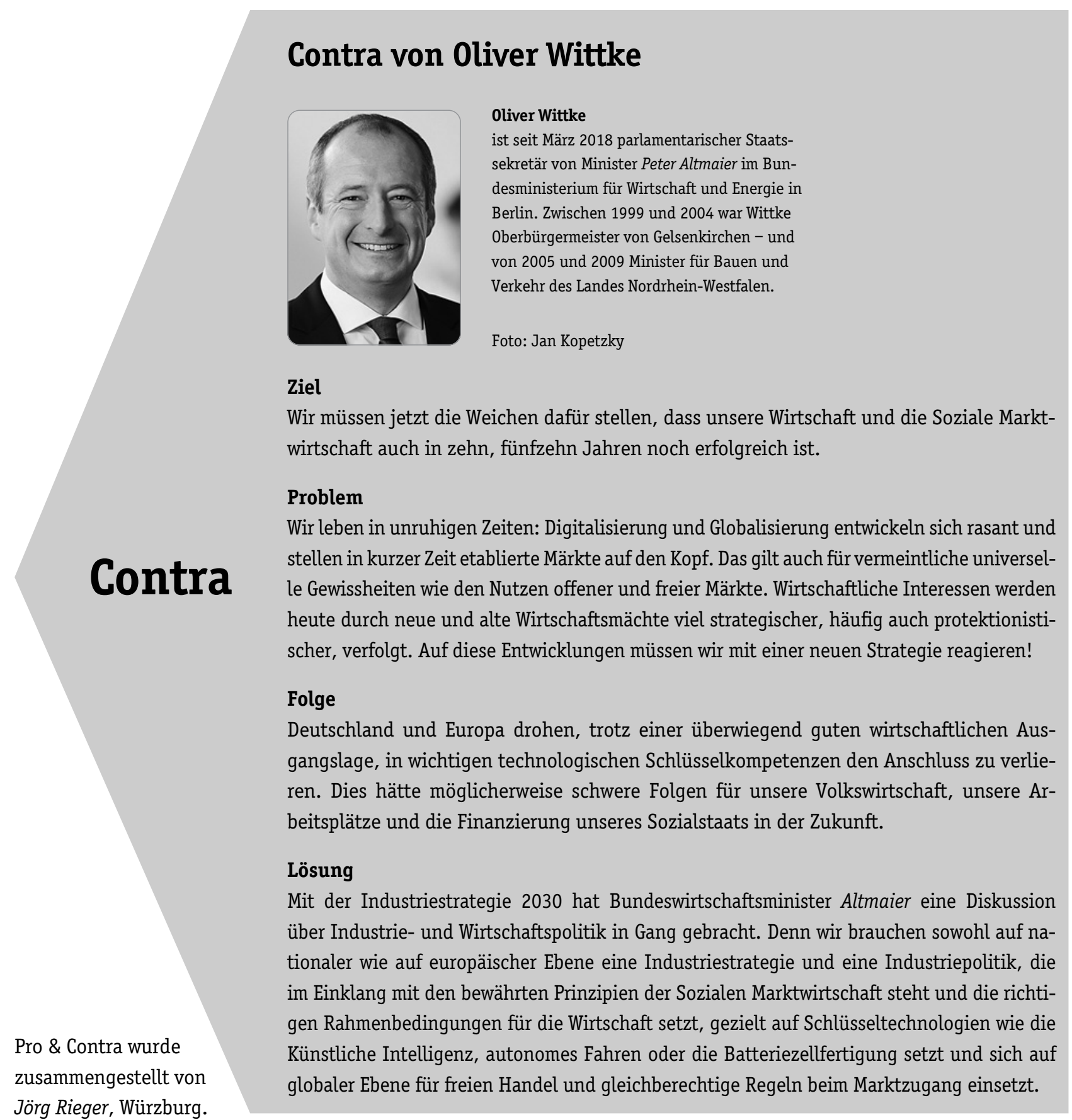

